alone. We have no doubt that this excellent little work will be a great success, but we should like the elementary principles of dynamics more amply illustrated. The introduction of the principle of limits on several occasions is highly commendable: the student should make its acquaintance early, but we believe in the old methods of proof to bring the matters more home to students, although they start, in a scientific view, from an inconsistency.-B. L.

Geodesy.-Studiın über höhere Geodasie. By Dr. C. Bremiker. (Berlin, r869.)

FROM great scientific undertakings, such as geographical expeditions, or geodetical, geological, and magnetic surveys of large areas, mankind generally derives, besides the utility of the work itself, a vast amount of contingent benefit. The result forms not only a landmark of scientific progress, but the work serves also for applying and testing a number of antecedent theoretical or practical discoveries, for separating what is sound from the unsound, and finally it rouses contemporaneously the mental energy of those more or less intimately connected with it to new exertions.

Of such a wide bearing is the great European arcmeasurement now in progress, in which for the first time the curvature of parallels of latitude will be simultaneously determined with that of the meridians, and the question will be decided whether the figure of the earth, as represented by the surface of the ocean, is really an ellipsoid of rotation, or whether a triaxial ellipsoid will have to be substituted for it. Of the mathematical, physical, and geodetical investigations, which the progress of this great work has already created, Dr. Bremiker's ranks among the foremost. It discusses the methods of reduction with reference to deviation of the plumb-line, latitude, azimuth, difference in longitude, latitude, and azimuth, small angles, deduction of triangles; and employs everywhere practical and interesting formulæ. The mathematical attainments necessary for understanding this excellent little work are not too high, and we feel certain that nobody who takes an interest in higher surveying will read it without extending his experience and knowledge.

B. L.

Our Bodies. By Ellis A. Davidson. (London : Cassell, Petter, and Galpin.)

WE cannot highly commend this little book, though we would wish to speak well of its author. $\mathrm{He}$ is evidently a thoroughly good and earnest teacher; and we have no doubt his oral lessons are far better than his written book, which may be described as "Goody Lessons in Physiology, written in words of either one or of more than five syllables." It consists of many terribly stony technicalities floating in a mass of very pappy information. On one page we find children warned, on physiological grounds, not to crack hard nuts with their teeth, and on another a description of the axis-cylinder of nerves, the white Substance of Schwann, and the canaliculi of bone. When will popular teachers of physiology and anatomy find out that these sciences are best taught free from technical hard nuts which splinter the enamel of the mind and worse? In not a few respects, too, we observe that "our bodies" of Mr. Davidson are not the same as our bodies.

The Intelligence of Animals.-From the French of

Ernest Menault. (London: Cassell, Petter, and Galpin.)

THE intelligence of animals may be studied in a scientific or in an anecdotal manner. M. Menault has chosen the latter method. We have not been led to form a very high opinion of his physiology or of his general philosophy; but he has compiled a most entertaining volume, crammed with most amusing stories about all kinds of animals, from ants to ourang-outangs. It is illustrated with numerous pictures, some of which are as good as the stories.

\section{EARTHQUAKE WAVES IN THE PACIFIC}

UNLIKE their great rivals, the Himalayas, which seem to have upreared themselves to a position where they can remain at rest, the Andes are disturbed from time to time by tremendous throes, whose effects are sometimes felt over a full third part of the earth's surface. To this class belonged the earthquake of August 13-14, 1868 , and in many respects it was the most remarkable of all the great earth-throes which have desolated the neighbourhood of the Peruvian Andes. As in the great earthquake which overthrew Riobamba in I797, a tremendous vertical upheaval seems simultaneously to have affected a region of enormous extent. But. terrible as were the direct effects of the first vertical shock and the others which followed, it was the action of the earth-throe on the ocean which caused the greatest devastation. It is hardly necessary to recall to the reader's remembrance the fearful effects experienced at Chala, at Arica, and at other places along the Peruvian shore; for few, doubtless, have forgotten how a countryman of our own described the ominous retreat of the ocean, and the overmastering fury with which it rushed back and swept far inland, destroying at once the shipping it carried with it, and the buildings which it encountered in its course.

So fearful a disturbance of the seas around the Peruvian shores could not but generate a widely-extended oscillation of the waters of the great Pacific Ocean. Yet

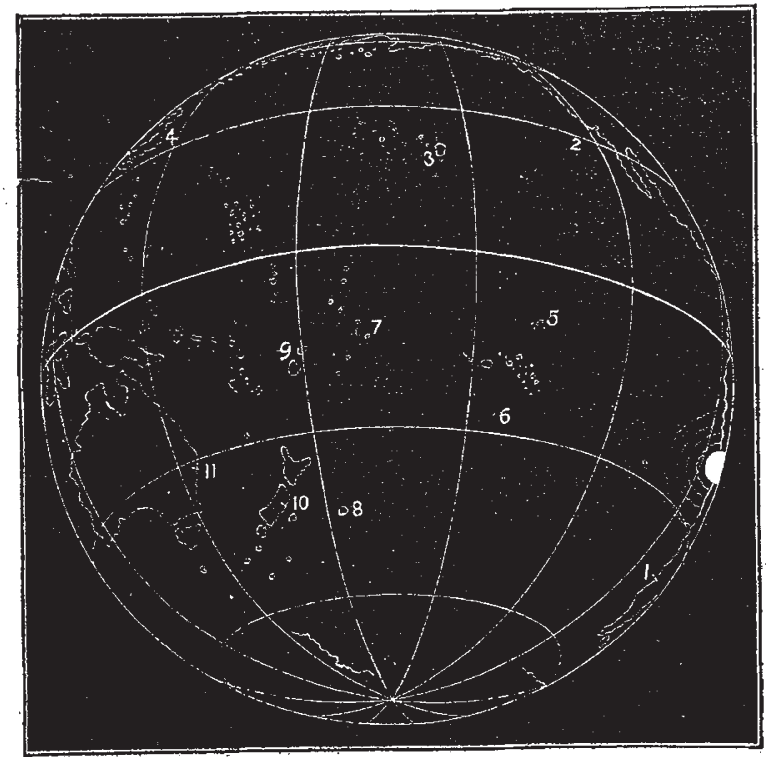

it is impossible to hear, without surprise, of the enormous waves which reached the far-off shores of the islands which lie scattered over that enormous ocean-tract. The accounts which came gradually in of waves which had swept past Honolulu and Hilo, into the ports of Yokohama and Lyttleton, and had even disturbed the waters which surround the East Indian Archipelago, seemed at first scarcely explicable as the direct results of a disturbance occurring so many thousands of miles from those places.

But when the accounts are carefully compared together, they are found to point most clearly to the South American shores as the true centre whence the great wave of disturbance had spread over the whole surface of the Pacific. Professor von Hochstetter* has brought together all the accounts which seem to throw light on the progress of the great earthquake-waves from Arica. For the most part, unfortunately, the waves visited the islands and ports of

* Petermann's "Geographische Mittheilungen," part vi. I869. 
the Pacific by night; but still enough evidence remains to exhibit with sufficient clearness the course which the disturbance followed.

Let us first endeavour to form a clear conception of the scene of this great manifestation of Nature's powers. The Pacific Ocean is not commonly chosen as the subject of a single map, and the maps in our ordinary atlases are not calculated to give clear ideas respecting the true shape and dimensions of an ocean which is undoubtedly the most remarkable physical feature of the whole terrestrial globe. I have endeavoured to remedy this defect by the accompanying chart, which represents a perspective view of that half of the globe to which the Pacific belongs, and will serve, I think, to convey a tolerably clear impression of the true proportions of this great ocean.

Near the shore of Peru I have marked the estimated region of central disturbance by a white circle.

The great waves which came surging onwards from the centre of disturbance must presently have lost their circular figure. On account of their enormous dimensions they "felt the bottom," so to speak, and were more or less retarded according as they traversed shallow or deep portions of the great ocean.

At Arica the first great shock of the earthquake was experienced at about five in the afternoon of August $13^{\text {th }}$. Twenty minutes later an enormous wave fifty feet in height swept in over the shores; and we may assume that about this time the waves which were about to traverse the Pacific started on their vast career.

Along the coast of Chili the wave travelled southwards, reaching Coquimbo three hours after the catastrophe at Arica. One hour later the wave had reached Valparaiso; and yet an hour later the inhabitants of Valdivia-marked (x) in the map-were terrified by an inrush of the sea which threatened to destroy their town.

Northwards from Arica the progress of the wave was not so carefully timed. On the I4th of August, but at what hour is not stated, the shores of Lower California, near San Pedro-marked (2) in the map--were swept by a wave no less than sixty-three feet in height.

At midnight of August I3-I4, the sea-wave reached the Sandwich Isles (3), and from that time until the 16 th of August the sea around those islands rose and fell in a surprising manner. It appeared as though the islands were first slowly raised as by some irresistible subterranean forces, and then suffered to subside until they seemed about to disappear for ever beneath the waves; nor was it easy to believe that in reality the sea alone was in motion.

Yokohama (4) was visited by the wave on August I4th, but unfortunately the exact hour is not known, otherwise there would have been the means of ascertaining how long a wave takes in traversing nearly a complete half of the earth's circumference.

The Marquesas Isles (5) were visited by waves of enormous dimensions before midnight of August r3th. Some of the islands of this group were indeed completely submerged by the crests of the principal waves.

At Opara (6), the coaling-station for steamships plying between Panama and New Zealand, nine waves came in one after the other, at intervals of twenty minutes, the highest sweeping over the coal depot.

At half-past two on the morning of August i 4 th, the watchman in Apiu, on the island of Opolu (7), aroused the frightened inhabitants from their sleep with the cry that the sea was coming in upon them; and during the whole of that day the sea rose and fell at intervals of only fifteen minutes. But the waves reached the Chatham Islands (8), though nearly as far from Arica, an hour and a half sooner. Three enormous waves rushed in upon these islands, one of which, the low-lying Tupunga, was completely submerged. Between two and three hours later the wave had reached the Fiji Islands (9).

The shores of New Zealand, and especially those bays of the southern island which face towards the east, were visited by enormous waves. Between three and four o'clock in the morning, the harbour of Lyttleton (10) was left completely dry by the retreat of the water, which did not return until more than an hour had elapsed. At five the water began again to retreat, reaching its lowest point an hour later. But at a quarter-past seven and at halfpast nine, and again at eleven, a great sea-wave swept over the bounds of the harbour.

Lastly, the ocean-wave visited the Australian shores near Newcastle ( $\mathrm{I}$ ) at about half-past six in the morning of August I4th, the waves gaining in height at each return until about half-past eleven, from which hour they slowly subsided.

The chief interest of these results lies in the circumstance that they enable us to form an estimate of the depth of the Pacific Ocean. Airy, Whewell, and other eminent mathematicians have shown how the velocity of sea-waves varies with the depth of the part of the ocean they are traversing. Where the breadth of the waves is great, as in the tidal wave, a very simple law connects the variation of the velocity with that of the depth. If a wave travels twice as fast in one part of its course as in another, it may be assumed that the depth of the ocean is four times greater in the former than in the latter part of the ocean. A tripled velocity signifies that the depth is nine times greater, and so on. With waves of different breadth the law is slightly different. But the following table, extracted from a larger one in Airy's paper on sea-waves (Encyclopcedia Metropolitana), shows how slightly the law is affected for waves beyond a certain breadth :-

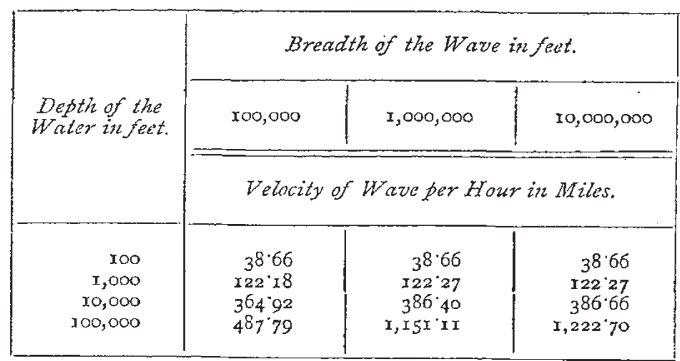

Observe, however, how in this table the wave Ioo,ooo feet in breadth remains relatively insensible of a change of depth from I0,000 feet to 100,000.

Now, Professor yon Hochstetter has carefully estimated the velocity of the wave which passed from Arica to the points marked (I), (3), (6), (7), (8), (IO), and (II) in the illustrative map, and his results may be briefly indicated as follows:-

$$
\begin{aligned}
& \text { Rate from Arica to station (x) . . 2 } 28_{4} \text { sea-miles per hour. }
\end{aligned}
$$

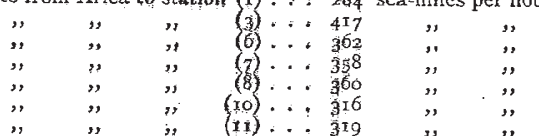

It is well to observe, first of all, how well the low rate of velocity to Valdivia accords with the theory of sea-waves, for this wave travelling along the sea-coast must have passed for the most part over shallows. The voyage to the Sandwich Isles appears to have been accomplished more rapidly than any of the others. Along the line, therefore, from Arica to (3), the Pacific has its greatest depth. Towards stations (6), (7), and (8), the sea-wave sped very swiftly, and here, therefore, the water is still deep, though not so deep as along the former route. But in voyaging onwards from the neighbourhood of the Chatham Isles (8) to New Zealand and Australia, the sea-wave lost a large portion of its velocity, insomuch that the average rate for this distance scarcely exceeds that with which the wave passed to Valdivia.

From these results it would be easy to calculate the mean depth of the ocean along the various tracks pur- 
sued by the wave-fronts. It will be found by those who care thus to apply Professor Airy's results, that the following estimates by Professor Hochstetter are approximately correct.

He makes the mean depth-

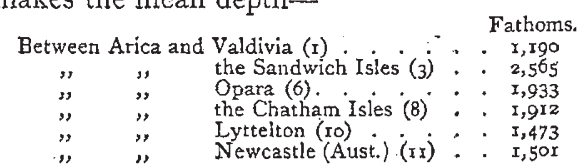

These results are the more valuable, because the Pacific Ocean has not been so carefully sounded as the Atlantic has. And though the progress of the tidal wave has long afforded similar evidence, yet a certain amount of doubt necessarily rests over conclusions drawn from the progress of a wave which is acted upon throughout its voyage across the Pacific by the attractions which gave it birth.

We may add, in conclusion, that on December 23, 18.54, a wave traversed the Pacific from Japan to San Francisco and Diego, or from (4) to the neighbourhood of (2), whose progress, dealt with according to Professor Airy's numbers, showed the mean depth of the sea between Japan and San Francisco to be 2, I49 fathoms, and between Japan and Diego 2,034 fathoms. These results agree fairly with those which have been deduced by Professor von Hochstetter.

R. A. PROCTOR

\section{A NEW FORM FOR SCHOOLS}

$A^{T}$

$T$ the first blush this may seem a trivial subject, but when we consider the immense floating multitude of children who frequent schools, spending at least some 6,000 hours on forms during the time that they are at school, and that their health may be injuriously affected by the use of unsuitable ones, the importance of the sub. ject hecomes evident.

Dr. E. H. Schildbach states, in the Gartenlaube, that amongst more than a thousand children whom he examined in several schools at Leipsic, he found only a few who did not show some lateral curvature or deviation of the spinal column, traceablc to the use of improper forms.

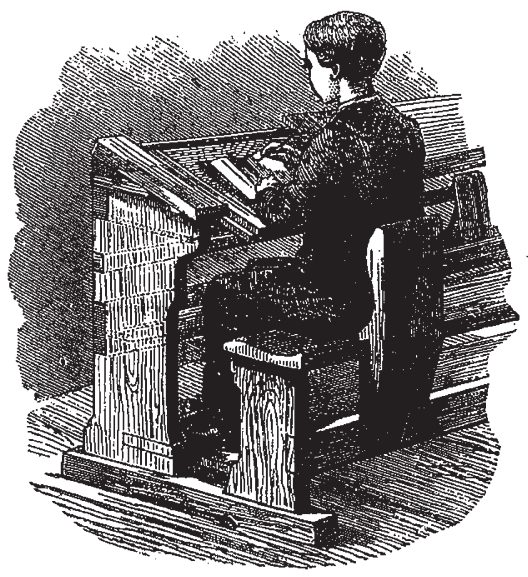

The chief defect in the construction of these forms was the great space between the seat and the table. Seats without backs soon tire out even robust children; they cannot sit upright for several hours together, and after much shifting from side to side, they are constrained to obtain relief by sitting on the very edge of the bench, and resting their arms on the table before them. The position into which they are thus forced is anything but a salutary one. The back is curved, especially in its lower half; the thorax sinks between the shoulders, and chest and stomach suffer a not inconsiderable pressure. To write in this position, one shoulder is raised much higher than the other, and the whole body is twisted unnaturally. With young and growing people the assumption of constrained positions, even for a few hours day by day, soon becomes habitual, and in many cases may lead to real deformity.

Our illustration represents the model form recommended by Dr. Schildbach, invented by $\mathrm{Mr}$. E. Kunze, of Chemnitz, in Saxony, and will scarcely require a detailed description. It will be seen that the table forms an inclined plane without the usual level projection at its upper part. It is divided by cross bars into separate desks and the boards which form the desks are movable and can be drawn out. A metal button with a lateral motion holds each board in its place, and also fixes it when drawn out. At the top in front are places for inkstands and writing materials, covered by the board when pushed home. Each seat has its separate back, of a shape best calculated to give proper support with the least possibhe pressure, while it allows the pupil to leave his place by stepping back over the seat without disturbing his neighbour. Underneath the table is a shelf. for books, slates, \&c., and beneath this there is a foot-board, an important provision against cold. The inexpensive character of this form and simplicity of its construction will be apparent to everyone.

\section{THE NOVEMBER SHOOTING-STARS}

THE earth is rapidly nearing the band of cosmical bodies to which the November star-showers owe their occurrence. Whether we are to witness a display or not depends wholly on the nature of that portion of the band through which we are to pass this year. The portion which gave the great display of 1866 has now passed many millions of miles away on its. course towards the orbit of the distant planet Uranus. Nearer to us, but still many millions of miles away, is the part which we traversed in 1867 , when (in America) there was a short but brilliant display of meteors, which would have afforded a yet more stiriking exhibition but for the full moon which dimmed their splendour. In I 868 meteors were seen in every part of the earth, and even, in America, on two successive nights. It is clear, therefore, that the portion of the band then traversed was very much wicler than the part through which the earth had passed in the two former years. But even the part traversed in 1868 is more than five hundred millions of miles away from us now ; and it is difficult indeed to say what may be the character of the portion we are approaching. Most probably it is even wider than the part we passed through in 1868 ; in which case we are sure (if the weather be but fine) to see a display of the November shooting-stars, though the same process of wide-spreading would of course tend to make the display so much the less brilliant.

It must be remembered that it will be absolutely useless to look for the meteors much before midnight of November 12-I 3 and of November 13-14. England does not come round to the exposed hemisphere of the earth-that is, to the hemisphere which is bearing directly through the meteor-band - much before ten o'clock in the evening; and she does not turn her full face, so to speak, towards the meteors before midnight. From that time until ten in the morning the rain of meteors is directed upon England without intermission, though no sign of the falling stars can be noticed after sunrise.

Our neighbours across the Channel propose to send observers to the shores of the Mediterranean, there to watch the meteors under more favourable circumstances than in more northern latitudes. Although we already know the principal conditions under which the meteors move, yet all observations directed to the determination of the size, colour, and constitution of these interesting bodies, will be well worth the making. The comet-nucleus 